\title{
RELEVÂNCIA JORNALÍSTICA: CONCEITO, FUNDAMENTOS E APLICAÇÃO
}

\author{
Journalistic Relevance: Relevancia periodística: \\ Concept, Fundamentals and Application concepto, fundamentos y aplicación
}

\author{
Josenildo Luiz Guerra* \\ *Universidade Federal de Sergipe, Departamento de Comunicação \\ Social, São Cristóvão, SE, Brasil \\ Liliane do Nascimento Santos Feitoza** \\ **Universidade Federal de Pernambuco, Recife, PE, Brasil
}

\begin{abstract}
Resumo: $\mathrm{O}$ conceito de relevância jornalística é pouco desenvolvido nos estudos de jornalismo e na prática profissional. Permanece uma medida obscura nos julgamentos que decidem a inclusão e o destaque de uma notícia no noticiário. Normalmente, os "valores-notícia", aqui concebidos como critérios de relevância, são explorados na literatura da área em uma perspectiva descritiva, que demonstra como são usados, sem entrar no mérito dos fundamentos que tornam um fato relevante nem dos métodos usados para proceder tal avaliação. O artigo propõe uma definição aplicada para o conceito, que complementa a contribuição dos trabalhos de viés conceitual-descritivo, como uma proposta de Pesquisa Aplicada em Jornalismo. Nessa perspectiva, baseado na definição de relevância de Sperber e Wilson (2005), apresenta o que considera ser o fundamento da relevância jornalística, as expectativas da audiência, e sistematiza a dinâmica de definição dos parâmetros de relevância, que chama de processo de avaliação de relevância.
\end{abstract}

Palavras-chave: Relevância. Jornalismo. Valores-Notícia. Pesquisa Aplicada.

\begin{abstract}
The concept of journalistic relevance is underdeveloped in the journalism studies, as with the profession itself. It is still an unapparent measure concerning the criteria to decide if a story becomes news, and how important that story might be. Normally, "news values" (defined here as criteria of relevance) are explored in the literature of this field within a descriptive perspective that describes and shows how they are used; however, it does not go into the merit of the fundamentals that make a fact important, nor does it describe the methods used to initiate such assessment. Thereupon, this article proposes: 1) an applied definition to the concept that supplements the contribution of descriptive and conceptual works (as an applied research proposal in the Journalism), aligned with Sperber and Wilson's relevance definition (2005); 2) a submission of what the basis for the relevance of journalism is: the audience expectations; and 3) a summary of the relevance parameters, known as relevance assessment process.
\end{abstract}

Keywords: Relevance. Journalism. News Values. Applied Research.

Resumen: El concepto de relevancia periodística es poco desarrollado en estudios de periodismo y en la práctica profesional. Cómo medida oscura permanece en los juicios que deciden incluir y despegar una

\footnotetext{
* Professor Titular do curso de Jornalismo e do Programa de Pós-Graduação em Comunicação da Universidade Federal de Sergipe (UFS). ORCID: http://orcid.org/0000-0001-5242-863X. E-mail: guerra.ufs@gmail.com.

** Doutoranda em Jornalismo pelo programa de pós-graduação em comunicação da UFPE. ORCID: https://orcid.org/0000-0002-3739-7721. E-mail: lilianensfeitoza@gmail.com.
} 
noticia en los periódicos. Por lo general, los "valores periodísticos", aquí concebidos como criterios de relevancia, se exploran en la literatura del área dentro de una perspectiva descriptiva, que demuestra cómo se usan, sin entrar en el mérito de los fundamentos que hacen que un hecho sea relevante, ni de los métodos utilizados para llevar a cabo tal evaluación. El artículo propone una definición aplicada para el concepto, que complementa la contribución de trabajos de sesgo conceptual-descriptivo, dentro de una propuesta de Investigación Aplicada en Periodismo. En esta perspectiva basada en la definición de relevancia de Sperber y Wilson (2005), presenta lo que considera la base de la relevancia periodística, las expectativas de la audiencia, y sistematiza la dinámica de definición de los parámetros de relevancia, lo que llama de proceso de evaluación de relevancia.

Palabras clave: Relevancia. Periodismo. Valores periodísticos. Investigación aplicada.

\section{INTRODUÇÃOO}

Um dos aspectos centrais do trabalho jornalístico é o processo de seleção dos fatos. Entre as razões possíveis para justificar as escolhas feitas está a avaliação de sua relevância. Alguns fatos apresentariam características que os tornariam dignos de ser notícia, ao passo que outros, não. A avaliação de relevância é importante para o jornalismo por duas razões básicas: toda organização jornalística tem uma capacidade limitada para processar fatos; e a audiência tem expectativas do que gostaria de ver contemplado no noticiário. Cada organização, no limite e de acordo com sua capacidade de produção, dedica-se aos fatos que potencialmente capturem a atenção de sua audiência e da sociedade.

Não obstante sua centralidade no âmbito da produção jornalística, a avaliação de relevância é um processo pouco transparente, o que reduz as possibilidades de discussões técnicas rigorosas acerca de seu julgamento. Vários pontos críticos evidenciam tal preocupação: o risco de critérios não jornalísticos superarem os critérios de relevância jornalística (interesses políticos, econômicos, pessoais, etc.); a clareza sobre os critérios usados para avaliar a relevância (identificação dos critérios); sua adequada aplicação aos fatos objeto do noticiário (correta associação do critério ao fato); a validade dos critérios empregados para operar os processos de avaliação (a existência de fundamento que sustente o critério como relevante); a escala de relevância entre os próprios critérios (o grau de relevância); a forma através da qual a avaliação é conduzida (o método); a regularidade metodológica na aplicação dos critérios (evitar dois pesos e duas medidas).

As questões acima são complexas, mas não é objetivo responder ao conjunto delas aqui. A pretensão é oferecer uma base a partir da qual possam ser analisadas, com o devido suporte teórico e técnico. O problema central deste artigo pode ser assim apresentado: o que é relevância jornalística, qual seu fundamento e como se a avalia no processo de produção da notícia? Essas questões colocam em discussão o objeto da relevância, a validade dos critérios e o processo de avaliação.

A resposta oferecida parte da premissa de que os valores-notícia são os indicadores da relevância, para, na sequência, 1) propor o fundamento que faz do valor-notícia um indicador de relevância; 2) definir o conceito de relevância jornalística, derivado do conceito de relevância de Sperber e Wilson (2005); e 3) propor um modelo explicativo do processo de sua avaliação no âmbito da atividade jornalística. 
Antes de seguir, é necessário deixar claro que o trabalho propõe uma inversão ao que apontaram alguns autores de referência para o estudo dos valores-notícia e dos critérios de noticiabilidade. Diferentemente de Galtung e Ruge (1999), Traquina (2004), Shoemaker e Cohen (2006) e Wolf (2009), para os quais a relevância aparece listada como um dos valores-notícia que operacionalizam a avaliação dos jornalistas, para este trabalho a relevância é uma grandeza maior, um requisito do Princípio Finalidade (como será explicado adiante), em função do qual os valores-notícia aparecem como seus indicadores sobre o valor jornalístico do fato.

Do ponto de vista metodológico, este artigo se insere no âmbito de uma Pesquisa Aplicada em Jornalismo (PAJ), pois "recorre a um conjunto de elementos teóricos e metodológicos voltados para compreender o fazer jornalístico e intervir nele de modo cientificamente orientado" (GUERRA, 2016, p. 202). Isso significa que a resposta ao problema proposto se desloca do viés conceitual-descritivo, como tem sido abordado tradicionalmente na área, para um viés aplicado, que elabora o conceito associado a sua dinâmica de operação na produção jornalística, tendo em vista a melhoria de desempenho.

Para realizar o movimento pretendido, o texto inicia com uma breve revisão de literatura do conceito de valor-notícia, ao fim da qual uma definição será estabelecida. Na sequência, a partir da noção de relevância de Sperber e Wilson (2005), sistematiza o processo de relevância jornalística e sua aplicação no âmbito da atividade. Ao concluir, sugere possibilidades a serem exploradas para se verticalizar os estudos com vistas à compreensão mais detalhada do conceito, que complemente, revise e construa novas relações e elementos pertinentes ao tema.

\section{VALORES-NOTÍCIA: CRITÉRIOS DE RELEVÂNCIA JORNALÍSTICA}

A preocupação com o que elege um fato à condição de notícia faz parte de um conjunto clássico de inquietações que estimula vários estudos. Identificados a partir de muitos termos, os critérios de seleção e hierarquização serão chamados aqui de valornotícia, incorporando a denominação de autores clássicos como Golding e Elliott e Wolf (2009), os primeiros citados por este último. Mas, já foram também identificados como critérios de escolha das notícias (ERBOLATO, 1978) considerações de adequação (GANS, 1979), atributos de relevância (CHAPARRO, 1994), valores informativos (LIPPMANN, 2010), elementos da notícia (WARREN, 1975), critérios de noticiabilidade (SHOEMAKER, 1991), entre outros.

Um amplo número de trabalhos se ocupou em listar critérios que devem ser priorizados, conforme levantado por Silva (2005) e Santos (2014). O primeiro a construir um quadro de referências, de acordo com Kunczik (1997), foi Tobias Peucer, na Alemanha de 1690. Depois, outros surgiram não apenas com novos assuntos e temáticas, mas também com sistematizações teóricas em torno das escolhas realizadas. A formação dessas listas vai caracterizar uma abordagem conceitual-descritiva dos critérios, isto é, um esforço centrado na identificação dos parâmetros usados pelos jornalistas ao avaliar os fatos. 
De forma a complementar essa abordagem conceitual-descritiva de tipos ou critérios, Golding e Elliott, citados por Wolf (2009), produziram uma das referências mais influentes para a compreensão dos valores-notícia: uma abordagem conceitual-descritiva de sua aplicação nos processos de produção jornalística. Para eles, os valores-notícia funcionam não só selecionando elementos dignos de inclusão no produto final, mas também como linhas-guia para a apresentação do produto. Ou seja, eles atuam também após a seleção, na medida em que auxiliam o jornalista a hierarquizar as informações selecionadas. Gans (1979) acrescenta que tais parâmetros não são classificações abstratas, mas critérios precisos, que podem ser aplicados com facilidade e rapidez, de forma que as escolhas possam ser feitas de maneira quase instintiva e automática.

Wolf (2009) não só categoriza os valores-notícia, mas também distingue valoresnotícia (cultura profissional), critérios organizacionais (cultura organizacional) e critérios de noticiabilidade (o filtro constituído pela aplicação simultânea de ambas as culturas). Silva (2005) segue nessa direção e considera que os critérios de noticiabilidade são um conjunto amplo de requisitos que age em todo o processo de produção, enquanto os valores-notícia são parte destes critérios dedicados especificamente a reconhecer as qualidades dos acontecimentos.

Guerra (2008, p. 226-227) reforça a distinção entre valor-notícia e critério organizacional. Para ele, valor-notícia está associado a características que tornam os fatos relevantes e os critérios organizacionais às condicionantes do processo de produção. É possível haver fatos que atendam aos valores-notícia, dada sua relevância, mas as condições de produção podem dificultar ou impedir sua cobertura. Com base nas contribuições desses autores (WOLF, 2009; SILVA, 2005; e GUERRA, 2008), é possível precisar a definição e o escopo de conceitos, muitas vezes confundidos: os valores-notícia são os critérios que avaliam a relevância dos fatos, no âmbito essencialmente técnico; os critérios organizacionais, as condições que parametrizam os processos de produção em uma organização; e os critérios de noticiabilidade, a junção desses dois grupos, os critérios técnicos entrecruzados aos critérios operacionais, que vão definir a inclusão de um fato no noticiário.

\section{AVALIAÇÃO DE RELEVÂNCIA NA PERSPECTIVA DA PESQUISA APLICADA}

Os trabalhos que se dedicam a definir e a listar valores-notícia o fazem a partir da perspectiva aqui chamada de conceitual-descritiva, porque voltada à caracterização seja dos tipos ou critérios, seja dos processos. Definem os valores-notícia, identificam seus tipos e como são operados dentro de uma organização jornalística. Essa abordagem oferece uma grande contribuição ao mostrar como se faz e com quais critérios, mas não entra no mérito sobre a eficácia dos métodos e dos critérios em relação à relevância efetiva que sugerem. Há uma diferença entre fazer, conforme a prática corrente descrita nas pesquisas, e fazer num patamar de desempenho melhor, que sugira o abandono de técnicas e processos inadequados ou ineficazes, ainda que consolidados, e vise qualificar tanto os processos de produção quanto os produtos jornalísticos. 
Para complementar as abordagens conceitual-descritivas, o artigo propõe o esforço aplicado, voltado a diagnosticar limitações (que indiquem qualidade insuficiente) a fim de propor melhorias e inovação (MACHADO, 2004; MACHADO, SANT'ANA, 2014; MEDITSCH, 2004; OCDE, 2005; FRANCISCATO, 2006). Esse movimento promoveria o deslocamento das perguntas sobre "quais são os critérios e como são aplicados nas organizações?" para questionar se "os critérios usados são os melhores?", se "o modo de sua aplicação é o mais correto?" e, ainda, "quais seriam os melhores critérios" e "qual o melhor método para sua aplicação?”.

Tal abordagem aplicada se estrutura em torno de dois princípios: o Princípio Finalidade e o Princípio Complementaridade. O primeiro sistematiza os papéis que a instituição jornalística se propõe ou é solicitada a cumprir na sociedade, mediante acordos e convenções estabelecidos socialmente que lhe atribuem um conjunto de responsabilidades (MCQUAIL, 2003). O segundo determina o respeito a eixos que, embora se refiram a questões de diferentes e específicas naturezas (teoria, ética, técnica, processos, tecnologia e sustentabilidade), juntam-se numa particular configuração para dar sentido e efetividade ao Princípio Finalidade, quando considerada a prática do jornalismo (GUERRA, 2016).

O Princípio Finalidade que está na base das reflexões aqui produzidas é:

- A atividade jornalística se destina a produzir livremente informações verdadeiras e plurais acerca de fatos reais do mundo, transmitidas por meio de algum suporte tecnológico, destinadas a compor uma agenda de questões que atenda às expectativas de relevância das audiências tanto em sua dimensão pública quando em sua dimensão privada, restringindo-se em ambos os casos a notícias sobre fatos que possam violar direitos e garantias individuais e coletivos reconhecidos como valores humanos universais.

Tal princípio se enquadra no paradigma da mediação, que oferece a base da compreensão clássica do jornalismo nas sociedades democráticas contemporâneas (MCQUAIL, 1992, 2003; CORNU, 1994; KOVACH, ROSENSTIEL, 2001; BERTRAND, 2002; FRANCISCATO, 2005; GENTILLI, 2005; MEYER, 2007; AUTOR, 2008; GOMES, 2009). Em que pese as críticas, as crises e limitações do paradigma (ROSCHO, 1975; ALTHEIDE, 1976; TUCHMAN, 1983; GENRO FILHO, 1987; HALL et al, 1993; MOLOTCH; LESTER, 1993; BARROS FILHO, 1995;), o presente trabalho se apoia em seus fundamentos e busca meios de aprimorar sua elaboração teórica e sua prática profissional.

Dos seis eixos associados ao Princípio Complementaridade, neste artigo serão desenvolvidos o teórico, o técnico e o processual. Serão feitas referências pontuais a outros, como o da ética, sem desenvolvê-los na mesma proporção dos primeiros. Apesar disso, a análise da relevância jornalística apresentada busca a convergência dos vários eixos, para que não se perca a dimensão sistêmica da atividade, aspecto central da proposta de pesquisa aplicada à qual se vincula este trabalho.

A literatura produzida sobre valor-notícia segundo o viés conceitual-descritivo foi fundamental para o nível de compreensão dos processos de seleção e de tratamento da notícia por organizações jornalísticas. É desse legado que o presente trabalho parte, a fim de incorporar uma perspectiva aplicada a essa área de estudos. Para que esse movimento 
possa acontecer, há uma pergunta capital que deve ser a primeira a ser respondida, a fim de que se entenda a natureza do problema: o que faz com que os valores-notícia tornem o fato relevante e digno de ser noticiável? Certamente, a resposta não pode ser "porque os jornalistas e as organizações jornalísticas os aplicam".

Para responder à questão e propor um modelo de compreensão do problema, o tópico a seguir parte de uma distinção entre valor-notícia como a) conceito e b) tipos ou critérios; e dentro do grupo b, tipos ou critérios, distinguir o Valor-Notícia de Referência (VNR) do Valor-Notícia Potencial (VNP) (GUERRA, 2008).

\section{VALORES-NOTÍCIA COMO EXPECTATIVAS DA AUDIÊNCIA: O FUNDAMENTO}

Guerra propõe uma diferenciação conceitual entre o valor-notícia como conceito abstrato, que expressa a noção de relevância jornalística, e as tipificações de valoresnotícia em si, isto é, os critérios ou tipos concretamente usados como indicadores de relevância (2008, p. 226-232). Essas tipificações são por sua vez divididas entre ValoresNotícia de Referência (VNR), valores tipificados e usados pelas organizações, de Valores-Notícias Potenciais (VNP), os tipos que podem ser levantados em função de novas demandas da audiência, da sociedade e de novos padrões editoriais.

Essa distinção é importante por duas razões. Primeiro, ao distinguir valores-notícia como conceito que expressa a necessidade de haver critérios para mensurar a relevância dos fatos, de VNR, os critérios efetivamente tipificados para avaliar relevância, fica claro que as listas produzidas e reproduzidas regularmente configuram o conjunto de critérios historicamente em uso pelas organizações. Esses VNR são valores-notícia, mas não esgotam os critérios que podem ser aplicados. Daí a possibilidade evidente de ValoresNotícia Potenciais (VNP), critérios novos que podem vir a ser incorporados às redações e tornar-se então VNR, em substituição a critérios usados que se mostrem inadequados ou em complemento a eles.

Segundo, a distinção permite fazer a seguinte pergunta-chave: o que faz de um valor-notícia um valor-notícia? A resposta passa pela necessidade de ir além das abordagens conceitual-descritivas de tipos e de processos para buscar o fundamento do valor-notícia. Ou seja, qual é a razão que faz o valor-notícia expressar a relevância de um fato? O valor-notícia se converte num critério de relevância porque representa uma expectativa de uso da parte da audiência (GUERRA, 2008, p. 180-188). Toda produção jornalística visa produzir uma informação para uma audiência, e consequentemente se orienta pelas expectativas presumidas que essa audiência possa ter. $\mathrm{O}$ valor-notícia delineia o perfil da audiência, oferecendo ao jornalista as referências do seu "leitormodelo" (ECO, 1993), em torno das quais deverá orientar sua produção.

As audiências são "tanto um produto de um contexto social (o que leva a interesses culturais, entendimentos e necessidades de informação comuns) quanto uma resposta a um padrão particular de fornecimento de mídia" (MCQUAIL, 1997, p.2). Necessariamente, em sua relação com uma organização jornalística, se constitui no conjunto empírico e potencial de receptores de suas matérias. Pode ser uma audiência "cativa", de acesso regular a um veículo, ou "flutuante", movida pelas circunstâncias. Na 
composição da audiência são implicadas caracterísicas de diferentes dimensões: espacial; de um grupo de pessoas; especificidades de um meio/canal; conteúdo da mensagem ou pelo tempo de consumo (MCQUAIL, 1997, p.2).

Tais características vão sugerir uma determinada competência de recepção, relativa ao conjunto de saberes que orienta a interpretação das notícias por seus membros. Por tratar-se de veículos distribuídos em grande escala, é razoável supor que dentro dela haja subgrupos, com perfis e competências distintos. Embora existam expectativas comuns que vinculem essa audiência a um determinado veículo, os diferentes subgrupos podem ter aproprições diferenciadas do noticiário disponibilizado.

A audiência gera dois tipos de expectativas: as de ordem privada e as de ordem pública (GUERRA, 2008, p. 232). As de ordem privada representam os gostos, preferências, interesses diretamente vinculados a demandas particulares. As de ordem pública representam os compromissos relacionados aos direitos e deveres que os cidadãos têm nas sociedades democráticas. Nesse segundo tipo, parte-se da premissa de que todos os indivíduos, quer queiram quer não, estão submetidos a vínculos formais de relacionamento - sociais, políticos e jurídicos, entre outros - decorrentes de sua condição cidadã.

Esse conjunto de expectativas, de algum modo, orienta a produção jornalística, através de uma demanda que se expressa na forma de valores-notícia. Entender a expectativa da audiência como fundamento de relevância do valor-notícia não significa o entendimento superficial de que os "gostos" da audiênca é que devam nortear o conteúdo jornalístico. Não se trata de fazer ou não uma "opção" pelo "gosto" da audiência. Tratase da constatação de que o conteúdo jornalístico só constitui audiência se suas mensagens provocarem sua atenção (MEYER, 2007, p. 15-42).

É uma condição necessária ao processo de comunicação, segundo os fundamentos da Teoria da Relevância de Sperber e Wilson $(1995,122)$. Para eles, a relevância da informação está relacionada à capacidade que tem de provocar algum tipo de efeito em quem recebe a informação. Esse efeito, em termos jornalísticos, começa pela atenção dos membros da audiência à noticia.

De certo, há uma responsabilidade ética do jornalista ao fazer uso de recursos voltados a captar a atenção de sua audiência. O processo jornalístico é complexo, e no qual há parâmetros que ora se cruzam, se sobrepõem ou se confrontam para definir quais devem predominar, em cada momento, no processo editorial. Parâmetros éticodeontológicos estão - ou deveriam estar - certamente no grupo de parâmetros mais fortes, a vincular os demais.

\section{A TEORIA DA RELEVÂNCIA DE SPERBER E WILSON}

Os estudos da relevância se desenvolveram em diversas escolas do conhecimento, conferindo um caráter interdisciplinar capaz de proporcionar investigações amplas e aprofundadas (GREISDORF, 2000). Para este trabalho, a referência é a obra de Sperber e Wilson (2001, 2005, 2010), linguistas orientados pela psicologia cognitiva, e as de outros autores, dedicadas a provocar, questionar ou somar conhecimento à sua produção, a exemplo de Costa (2005, 2008) e Rauen (2007, 2008). 
Sperber e Wilson (2001) consideram que é a busca pela relevância que justifica a obtenção de determinados significados e não de outros na interação comunicativa entre dois agentes. Para eles, a cognição humana será sempre dirigida à maximização da relevância, o que se deve à evolução da espécie e ao papel que a cognição desempenha nesta evolução. A necessidade de priorizar as entradas relevantes se fundiu à cognição humana como uma necessidade de sobrevivência, atuando tanto na percepção seletiva dos estímulos e suposições quanto em sua interpretação (SPERBER; WILSON, 2005, p. 182). A teoria da relevância entende que a cognição evoluiu ao ponto de pré-selecionar, entre todos os fenômenos disponíveis, os previamente dignos de atenção.

Com base nas premissas e definições dos autores, a relevância comunicativa é uma propriedade dos inputs, medida sempre em um determinado contexto, que se define pela geração de efeitos cognitivos positivos para um determinado indivíduo, mas se gradua pelo equilíbrio entre os efeitos e os esforços requeridos para se alcançá-los (SPERBER; WILSON, 2001, 2005). A busca por relevância seria a busca pelo desempenho eficiente da cognição em cada contexto, precisando para tanto balancear custos e benefícios (FEITOZA, 2016, p. 40).

O contexto, nesta definição, é "uma construção psicológica formada por um conjunto de suposições que o ouvinte tem do mundo" (SPERBER; WILSON, 2001, p. 45-46). É classificado como relevante o input que, ao acionar o contexto do indivíduo, promove uma diferença vantajosa, aperfeiçoa ou amplia sua compreensão do mundo, ao ponto de estimular ações. Certamente, a ênfase é no "contexto" do indivíduo, mas não se desconsidera que este "contexto individual" é resultante da interação com contextos sociais, culturais e históricos que se constituíram e se constituem continuamente de modo entrelaçado.

O conceito de relevância pode ser explorado em três dimensões complementares: classificatória, comparativa e quantitativa. Na classificatória, a relevância é definida em torno dos efeitos cognitivos que é capaz de gerar. "Uma suposição é relevante para um indivíduo em um dado momento se e somente se ela tem efeito cognitivo positivo em um ou mais contextos acessíveis a ele nesse momento" (SPERBER; WILSON, 2005 p. 187). O efeito cognitivo positivo gera uma diferença vantajosa na percepção de mundo do sujeito, quando um input se conecta a informações que já fazem parte de um repertório de informações (o contexto) e é capaz de aperfeiçoar, melhorar ou ampliar esse repertório (SPERBER; WILSON, 2005).

A dimensão comparativa também define a relevância pela geração de efeitos cognitivos positivos, mas considera também os esforços requeridos, sob duas condições. A condição de grau 1 destaca a relação entre relevância e efeitos: "uma suposição é relevante para um indivíduo na medida em que os efeitos contextuais positivos obtidos, quando ela é otimamente processada, são amplos" (SPERBER; WILSON, 2005, p. 187). Já a condição de grau 2 chama a atenção para o esforço: "uma suposição é relevante para um indivíduo na medida em que o esforço requerido para obter esses efeitos cognitivos é pequeno" (SPERBER; WILSON, 2005, p. 187).

A dimensão quantitativa, pouco explorada pelos autores, destaca que a relevância não se manifesta apenas em níveis de presença ou ausência, mas pode atingir diferentes graus (SPERBER; WILSON, 2005, p. 224). Apresentados os termos nos quais Sperber e Wilson definem a relevância, o tópico seguinte é dedicado a aplicar suas bases ao conceito de relevância jornalística. 
Para aplicar a definição de Sperber e Wilson ao processo jornalístico, será preciso identificar, no âmbito da atividade: 1) os inputs específicos da comunicação jornalistaaudiência; 2) o contexto cognitivo considerado para se avaliar a geração de efeitos positivos para o indivíduo e, consequentemente, qual é o indivíduo a ser considerado para efeito da avaliação de relevância; e 3) os esforços que dizem respeito à geração dos efeitos pretendidos.

O processo de avaliação de relevância jornalística se dá no âmbito da relação comunicativa entre jornalistas (em suas organizações) e a audiência. Nesta relação, a audiência oferece expectativas de ordem pública e privada (sistematizadas na forma de valores-notícia), que se convertem em demandas relativas a fatos a serem contemplados pelos jornalistas. Estes entregam as notícias que se espera satisfaçam as expectativas daquela (Figura 1).
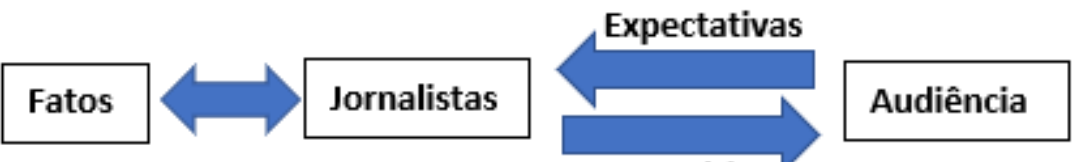

Notícias

\section{Figura 1 - Esquema básico da relação comunicativa entre jornalistas/organizações e a} audiência

Fonte: Elaboração própria.

O processo de avaliação de relevância ocorre em dois estágios: 1) interno à organização, quando relativo ao julgamento de relevância feito no ato da produção jornalística pelos jornalistas; e 2) externo à organização, quando relativo ao monitoramento da relevância percebida pela audiência, no ato da recepção. $\mathrm{O}$ segundo estágio capta feedbacks da audiência que permitam avaliar a eficácia do processo de avaliação em seu primeiro estágio (Figura 2). Em ambos os estágios, a atenção primária, a partir da qual se processa inicialmente a avaliação de relevância, se converte em atenção consolidada na medida que o fato (no estágio 1) ou a notícia (no estágio 2) sejam considerados relevantes. 


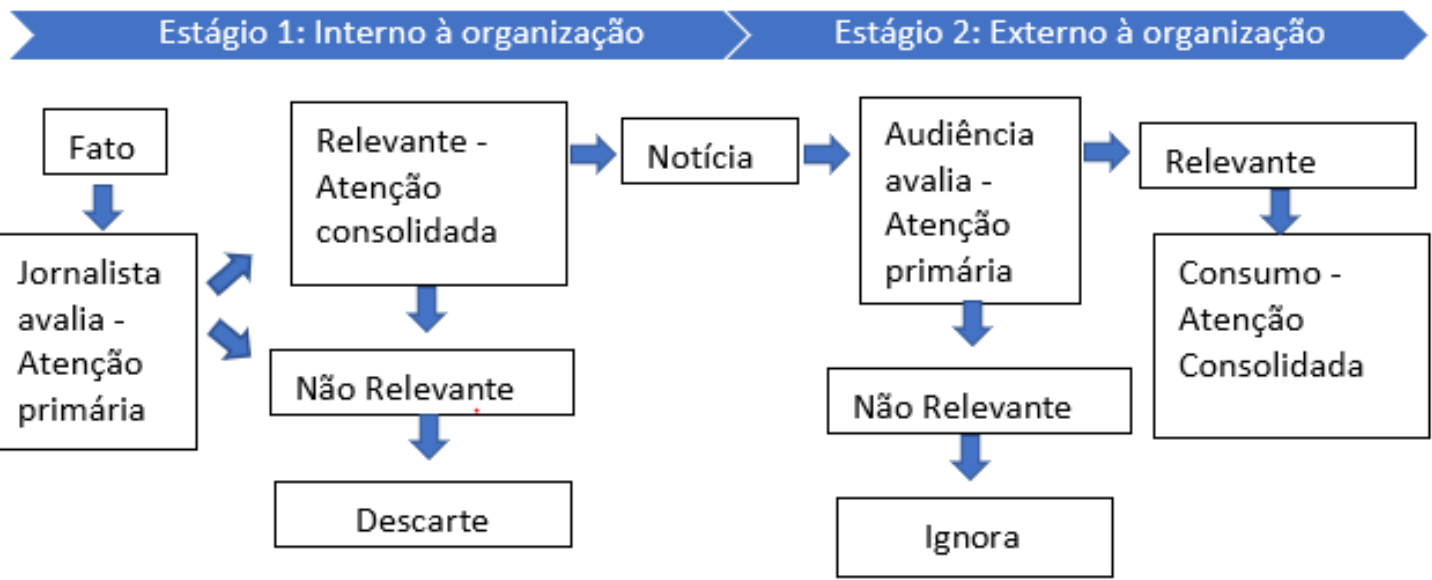

Figura 2 - Processo de avaliação de relevância em dois estágios

Fonte: Elaboração própria.

A relevância jornalística se manifesta concretamente em cinco momentos: 1) a Expectativa de Relevância (ER), demanda prospectada junto à audiência (através de processos de sondagem de opinião, por exemplo); 2) a Relevância Percebida pela audiência (RP), prospecção do que atraiu efetivamente a atenção da audiência e, numa perspectiva ampliada, das agendas pública, governamental e de outros veículos jornalísticos; 3) os Valores-Notícia de Referência (VNR), conjunto de critérios de relevância operado por uma organização jornalística, de acordo com seu projeto editorial (elaborados a partir da ER e também da RP); 4) a Relevância Primária (RPri), avaliação de relevância dos fatos pelos jornalistas a partir dos VNR; 5) a Relevância Projetada (RPro), relevância atribuída ao fato na edição, a partir dos VNR. Quanto mais convergentes forem esses cinco momentos, menos conflitos haverá entre a audiência e os jornalistas em relação à relevância dos fatos objeto de notícia.

Convém destacar que a Expectativa de Relevância (ER) constitui um ponto formal para início do ciclo, que, entretanto, é contínuo. Ela expressa uma relevância que se pretende ser do domínio mental da audiência, mas em alguma medida já é também do domínio da organização, através dos instrumentos metodológicos empregados pela segunda para a captação da primeira. Por isso, na Figura 3 aparece como um momento de transição entre os dois domínios mentais em interação. O Valor Notícia de Referência (VNR), a Relevância Primária (Rpri) e a Relevância Projetada (RPro) são do domínio mental do jornalista, atravessado pelos saberes organizacionais e institucionais assimilados. Já a Relevância Percebida (RP) pertence ao domínio mental da audiência. 


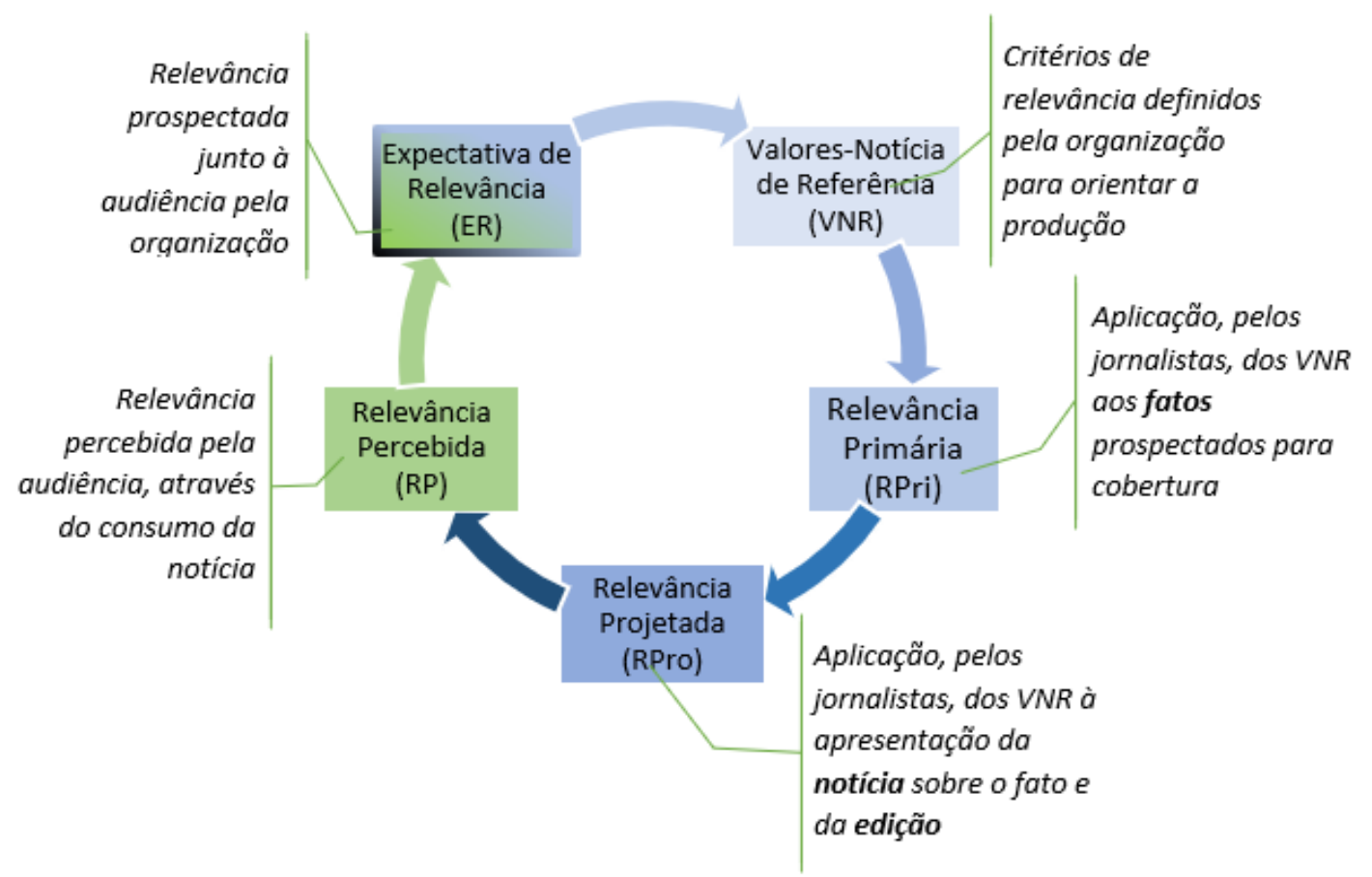

Figura 3 - Momentos concretos nos quais a relevância jornalística se manifesta

Fonte: Elaboração própria.

As figuras 1, 2 e 3 elaboram aspectos básicos que serão melhor destacados na sequência, através do detalhamento de como se processa a avaliação de relevância no âmbito da atividade jornalística. Para isto, entretanto, é necessário entender o processo jornalístico e como nele está inserido o processo de avaliação de relevância.

O jornalista, ao realizar seu trabalho, realiza o percurso interpretativo que opera dois movimentos simultâneos: produzir um conhecimento verdadeiro sobre o fato e avaliar o valor jornalístico do fato, com base nos VNR, a fim de decidir por sua inclusão e destaque no noticiário. Cada movimento é conduzido por dois tipos de saberes: as Técnicas Cognitivas de Processo (TCP) e as Técnicas Cognitivas de Conteúdo (TCC) (GUERRA, 2008).

As Técnicas Cognitivas de Processo (TCP) abrangem três tipos de conhecimentos: institucionais, relativos ao domínio de normas e conceitos da atividade jornalística (ver TRAQUINA, 2004; FRANCISCATO, 2005; North, 1990, como citado em FENGLER et al., 2014); organizacionais, relativos ao domínio de normas e conceitos operados no âmbito de um grupo concreto de pessoas dedicado a produzir notícias; e ambiente de convivência, saberes práticos relativos às condições de operação, que envolve as relações entre pessoas, o uso de equipamentos, sua disponibilidade, etc.

As Técnicas Cognitivas de Conteúdo (TCC) operam saberes relativos às áreas temáticas e às expectativas da audiência. As primeiras representam os conhecimentos necessários à interpretação dos fatos. Quem deseja cobrir política, por exemplo, precisa conhecer a dinâmica, os atores e os processos políticos. As segundas representam os saberes sobre as expectativas da audiência, e se revelam exatamente no domínio dos VNR que, presume-se, expressam aquelas expectativas. 
A Figura 4 ilustra as relações entre os momentos de manifestação da relevância jornalística no âmbito do percurso interpretativo na produção da notícia. Há uma relação presumida de mútua acomodação entre expectativas de relevância da audiência e a avaliação de relevância dos jornalistas. A célula competência de recepção/expectativa de relevância atua sobre a audiência, na geração de sua efetiva Relevância Percebida em relação a uma notícia, ao passo que atua também no médio/longo prazo sobre a própria formação dos VNR. A audiência, ao receber uma notícia, interage com ela, sobre a qual lança suas próprias expectativas que, se confirmadas, poderão levá-la da atenção primária à atenção consolidada, em diferentes graus.

O jornalista opera como um mediador, voltado a atender às expectativas da audiência e atrair sua atenção. Ao ser colocado diante dos fatos, lança sobre eles os VNR para filtrar os que potencialmente atenderão à audiência. Nessa abordagem, opera um conjunto de técnicas cognitivas voltadas para, entre outros objetivos envolvidos no processo de produção, projetar a relevância da notícia que julga a mais eficaz para ser acolhida pela audiência (RP). Esse acolhimento não representa, necessariamente, um juízo de valor (aceitação ou rejeição) sobre o conteúdo, mas apenas a decisão de consumir a notícia.

Ao tempo em que a audiência expressa uma Expectativa de Relevância, os jornalistas, em suas organizações, elaboram e reelaboram (no médio e longo prazo) tais expectativas nos VNR, e, cotidianamente, propõem fatos que se adequem a elas. A audiência, através de sua Relevância Percebida, sinaliza a acolhida ou não do que lhe foi oferecido. Essa relação comunicativa nunca pode ser considerada apenas de mão única, mas de profunda interação. As partes tentam gerar efeito uma na outra, estimulando sua atenção para aquilo que cada qual considera relevante.

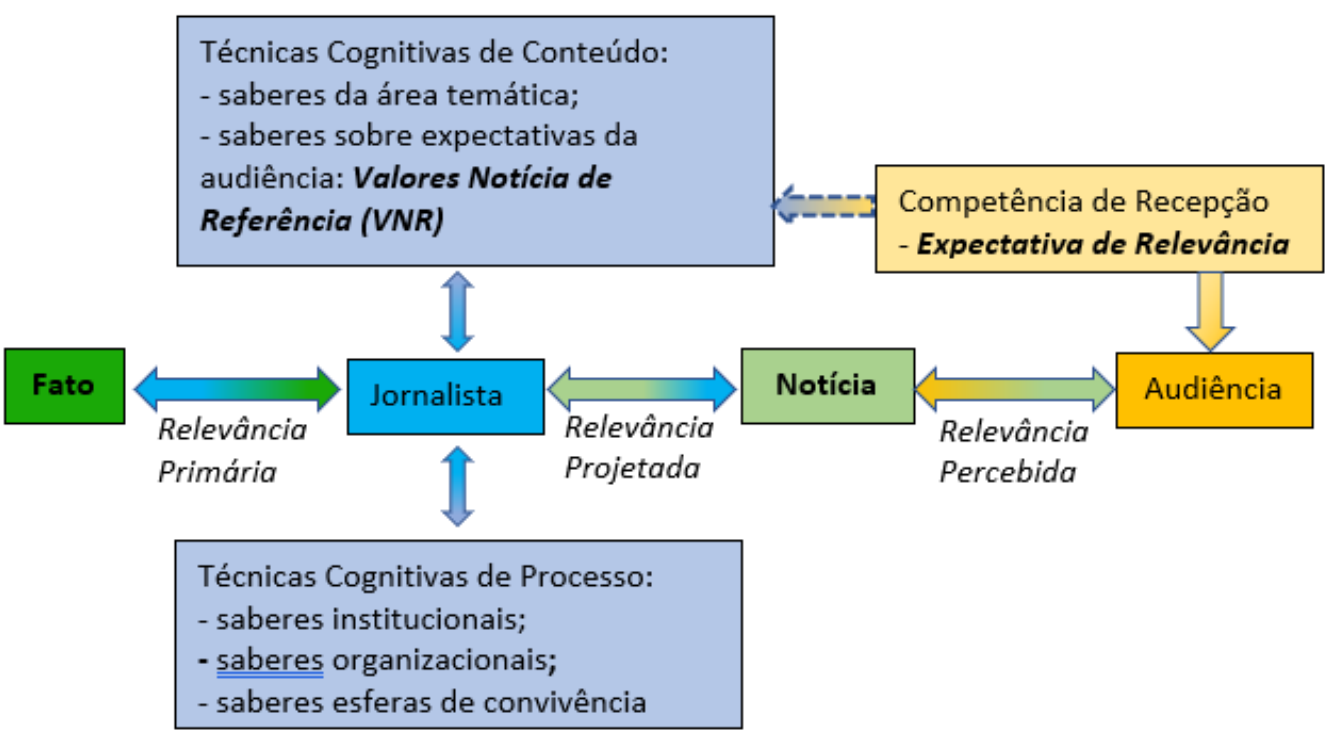

Figura 4 - Esquema básico do processo de avaliação de relevância durante o percurso interpretativo na produção da notícia

Fonte: Elaboração própria. 
A partir dessa configuração do processo de avaliação de relevância, vai-se aprofundar e detalhar os componentes que o caracterizam, a saber: 4.1) os inputs, 4.2) o contexto cognitivo e os indivíduos, e 4.3) os esforços requeridos.

\subsection{OS INPUTS DA COMUNICAÇÃO JORNALÍSTICA}

Segundo Sperber e Wilson (2001), um input pode ser de dois tipos: interno (suposições) ou externo ao indivíduo (estímulos). No Estágio 1 (interno), as suposições são os VNR, que vão atuar nas três dimensões: classificatória, comparativa e quantitativa. Os saberes organizacionais vão atuar principalmente na dimensão comparativa, ao dimensionar o esforço requerido para processar o efeito de relevância, que poderá impactar na dimensão quantitativa (a gradação de relevância dos fatos). Esses saberes são internos porque constituem parte do conhecimento profissional assimilado pelos jornalistas.

Já os estímulos são dois: as expectativas da audiência, que moldam os VNR, e os fatos, que provocam os jornalistas a aplicar sobre eles os VNR (geração de efeito) e as condições organizacionais de produção (administração do esforço). Sob a influência desses inputs, a notícia será produzida conforme os VNR e os esforços que o jornalista avaliou adequados ao fato que constitui seu objeto.

Os inputs do Estágio 2 (externo) são a notícia, como estímulo, e a competência de recepção da audiência, como suposição. Os membros da audiência vão interpretar a notícia e, a partir de suas suposições, podem ou não receber os efeitos pretendidos pelo jornalista. Estímulos secundários, como a opinião de outras pessoas, podem afetar suas suposições. A relevância percebida por eles vai fechar o ciclo, acolhendo ou não a Relevância Projetada na notícia. Esse feedback retroalimenta os jornalistas sobre a validade dos VNR e das expectativas de relevância prospectadas até então.

Ao ter o processo externo como parte do processo de avaliação de relevância, considera-se que o processo de avaliação interno só se conclui, como possibilidade de mensuração de sua eficácia, com a aceitação ou não da Relevância Projetada pela audiência. Mas, igualmente se considera que, estritamente, o processo jornalístico de produção noticiosa se dá no âmbito do Estágio 1, relativo ao processo de avaliação de relevância interno.

\subsection{O CONTEXTO DE PROCESSAMENTO DOS INPUTS E O INDIVÍDUO}

A relevância de um input está, necessariamente, associada a um contexto. Em Sperber e Wilson (2001), um estímulo ou uma suposição só será relevante quando gerar algum efeito cognitivo. Em cada um dos estágios do processo de avaliação de relevância participam seus respectivos indivíduos com seus respectivos contextos.

No processo de avaliação interno, o indivíduo é o jornalista, o operador dos saberes a gerenciar os inputs. O indivíduo jornalista opera como representante da instituição jornalística e da organização pela qual atua. É ele o indivíduo cujo contexto deverá 
receber o efeito provocado pelos estímulos (os fatos) e pelas suposições (as técnicas cognitivas que administram os VNR e as condicionantes organizacionais). Os efeitos provocados pelos fatos e as técnicas cognitivas, entretanto, são relativos às suposições que o jornalista tem em relação aos efeitos que pretende gerar (capturar a atenção) na audiência, isto é, à imagem que tem da audiência como seu leitor-modelo, forjada, em boa medida, pelos VNR.

Os saberes acionados pela racionalidade profissional das técnicas cognitivas conduzem a análise dos fatos passíveis de cobertura, ainda que existam outros aspectos intervenientes, aqui não desenvolvidos. Ao projetar tais técnicas (suposições) na análise dos fatos, o jornalista precisa se sentir convencido do valor jornalístico do fato. Quando isso acontece, configura-se o efeito cognitivo que sinaliza a Relevância Primária. Ele considera estar diante de um fato que poderá interessar a sua audiência e, a depender do caso, repercutir junto às agendas públicas, governamental e inclusive midiática. Quanto maior repercussão provocar, maior a Relevância Percebida por essas instâncias, o que confirmaria o juízo de valor produzido pelo jornalista, seja no momento da Relevância Primária, seja no da Relevância Projetada.

No processo externo, o indivíduo é cada membro da audiência que se expõe à notícia. Por se tratar de pessoas que podem compartilhar competências de recepção, é possível que compartilhem também a Relevância Percebida. Mas, como as audiências não são necessariamente homogêneas, seus membros podem ter diferentes percepções de relevância em função de sua diferenciada competência de recepção. A recepção dos membros da audiência nunca é, portanto, homogênea, mas para a eficácia do processo comunicativo baseado na relevância das mensagens é imprescindível que, de algum modo, a audiência e a sociedade respondam aos efeitos pretendidos pelos jornalistas.

\subsection{O ESFORÇO REQUERIDO PARA ALCANÇAR O EFEITO COGNITIVO POSITIVO}

Na definição comparativa da relevância, Sperber e Wilson (2005) indicam que, além dos efeitos, a relevância sofre influência dos esforços, de modo que uma suposição é relevante na medida em que os esforços requeridos para alcançar os efeitos sejam compensáveis.

No processo interno, consideram-se três tipos de esforços, tanto no âmbito da Relevância Primária quanto no âmbito da Relevância Projetada. O primeiro é a complexidade da área temática e do fato objeto de cobertura. Quanto mais complexa a área, maior o esforço do jornalista para acessar os saberes adequados à intepretação do fato. Quanto mais complexo o fato, maior o esforço para apurá-lo, entendê-lo e apresentálo à audiência. Nos dois casos, o esforço a ser aplicado - assim como a própria avaliação do esforço necessário - pode afetar a mensuração de relevância do fato.

O segundo tipo de esforço diz respeito ao gerenciamento das condicionantes organizacionais em relação à capacidade de produção. Os fatos serão confrontados com as condições disponíveis, tais como tempo, equipe e recursos, que podem não ser suficientes para dar conta deles em função da Relevância Primária avaliada, ainda que elevada. Eis que se torna necessário um esforço adicional, se possível, para viabilizar a 
cobertura; ou uma simplificação do trabalho ou seu abandono quando tal esforço não for possível. Uma organização que disponha de meios em abundância ou melhor gestão dos recursos existentes tem potencializado o trabalho de produção, e consequentemente poderá operar com margem de esforço menor que permita considerar, em maior proporção, o efeito provocado no momento da avaliação da Relevância Primária e consequentemente no da Relevância Projetada.

O terceiro tipo de esforço está relacionado à apresentação da notícia, e afeta, especificamente, a Relevância Projetada. O jornalista se esforça para criar estímulos ostensivos que, além de acionar a atenção primária da audiência, possam diminuir seu esforço interpretativo. A Teoria da Relevância propõe uma separação entre a intenção de informar e a intenção de comunicar, indicando que a intenção informativa pretende levar alguma informação ao receptor, enquanto a intenção comunicativa pretende informar o receptor sobre a intenção informativa do emissor (SPERBER; WILSON, 2001, p. 65).

O jornalista realiza o esforço de produzir a) recursos que chamem a atenção da audiência (como os títulos, por exemplo), a fim de alertar sobre sua intenção comunicativa da Relevância Projetada; e b) uma mensagem adequada ao nível presumido da competência de recepção da audiência, a fim de efetivar sua intenção informativa sobre o fato noticiado. Trata-se, neste caso, da busca pela "relevância ótima", a relevância merecedora do processamento mais compatível entre os interesses e disponibilidades do receptor e do enunciador (SPERBER; WILSON, 2005, p. 190-193). Exemplos disso são os casos nos quais o jornalista precisa empregar um grande esforço no sentido de "traduzir" informações complexas, com o objetivo de torná-los compreensíveis a sua audiência (LAGE, 1999). O esforço não pode ser visto como algo que limite a avaliação de relevância, mas como um componente necessário do processo, seja para gerenciar a produção, seja para cultivar a audiência.

Um aspecto relacionado ao esforço é a variável da exaustão, que funciona moderando a relação custo-benefício. "Em igualdade de condições, quanto mais exausto estiver o organismo, maior será o dispêndio de energia para compensar o efeito cognitivo, minimizando a eficiência cognitiva ou relevância de um fenômeno até um ótimo de Pareto" (RAUEN, 2008, p. 41). A variável da Exaustão de Rauen se propõe a enriquecer o princípio cognitivo de relevância, baseando-se na percepção de que os seres humanos não atuam em um estado permanente de captura de informações, mas alteram estados tensos e distensos, nos quais a cognição opera guiada ora pelos efeitos, ora pelos custos.

Em função disso, duas considerações são necessárias: as condições de trabalho do jornalista são importantes para proporcionar uma relação adequada entre o esforço exigido tanto dele quanto do aparato organizacional e as relevâncias primária e projetada; e a oportunidade do uso de estratégias de distensão (como o balanceamento numa edição entre hardnews e softnews) podem ser úteis para proporcionar algum relaxamento aos membros da audiência a fim de recuperar a energia necessária às informações mais complexas. 
$\mathrm{O}$ artigo procurou apresentar e fundamentar a proposta de valor-notícia como um conceito que mede a relevância dos fatos a partir da Teoria de Relevância de Sperber e Wilson. Tal movimento se deu, do ponto de vista metodológico, na perspectiva de uma Pesquisa Aplicada em Jornalismo (PAJ), a fim de complementar o amplo esforço conceitual-descritivo produzido por importantes trabalhos dedicados ao tema. Como resultado, pretendeu-se entregar uma definição de relevância e de seu processo de avaliação, cuja proposta explica e orienta a prática profissional, assim como sugere meios de mensuração de desempenho e de qualidade editorial.

Em síntese:

- A relevância jornalística é um juízo de valor jornalístico do fato, em função dos efeitos que pode gerar na audiência. Tal juízo resulta da aplicação de Valores-Notícia de Referência aos fatos potencialmente jornalísticos, graduada pelos esforços necessários para a busca dos efeitos pretendidos. O processo de avaliação de relevância se dá em dois estágios: 1) interno, quando os jornalistas avaliam a Relevância Primária e projetada dos fatos; 2) externo, quando a audiência avalia a relevância da notícia publicada.

O conceito de relevância jornalística e do processo de avaliação de relevância, aqui propostos, exigem certamente desenvolvimento com vistas a aprimorar e a detalhar as muitas implicações possíveis e cuja exploração é necessária. De nossa parte, destacamos especialmente três:

- A relação entre esforço e efeito no âmbito da Relevância Primária (RPri): o esforço no âmbito da RPri se dá durante o processo de produção da notícia, quando o efeito cognitivo percebido pelo jornalista será confrontado com o esforço organizacional e profissional necessário para a apuração do fato. Se há a condição de que o efeito deva ser ajustado ao esforço, não decorre, contudo, que o esforço seja o determinante para a avaliação da relevância. Nesse caso, o jornalista e sua organização devem mensurar adequadamente o efeito percebido com o esforço necessário para atingi-lo, e não renunciar ao efeito em virtude do esforço (se grande) a ser realizado. Se o baixo esforço do jornalista e da organização for a regra, igualmente será regra, provavelmente, a baixa qualidade do serviço noticioso oferecido à audiência, na avaliação da RPro.

- A relação entre esforço e efeito no âmbito da Relevância Projetada (RPro): o esforço da audiência na interpretação de uma notícia está fora do controle do jornalista. Deste esforço, contudo, resultará a Relevância Percebida (RP), que poderá divergir da Relevância Projetada (RPro). Entretanto, cabe ao jornalista operar para diminuir o esforço requerido da audiência a fim de elevar as chances do efeito pretendido, através da análise do nível de profundidade necessário na abordagem do fato, a partir de sua avaliação da RPri; e da estratégia de apresentação da notícia, a fim de torná-la mais facilmente assimilada por sua audiência.

- As relações e tensões existentes nos pontos de correspondência entre os momentos da relevância sugerem vários pontos críticos:

a) relação entre Expectativa de Relevância (ER) e Valores-Notícia de Referência $(V N R)$ : é necessário que as expectativas de relevância sejam adequadamente processadas 
e convertidas em VNR que de fato as reflitam. Se as expectativas não forem adequadamente prospectadas, podem gerar VNR equivocados a gerir todo o processo. Se as Expectativas de Relevância forem adequadamente prospectadas, mas os VNR não forem adequadamente extraídos, igualmente VNR equivocados irão nortear todo o processo de produção de notícias;

b) relação entre Valores-Notícia de Referência (VNR) e Relevância Primária (RPri): considerando a hipótese de que os VNR representem adequadamente as Expectativas de Relevância (ER), outro ponto crítico será a aplicação desses valores aos fatos objeto de cobertura. Os jornalistas podem aplicá-los ou não corretamente. Se não aplicarem corretamente, poderão incluir ou excluir fatos no noticiário em dissonância com a ER que moldaram os VNR e, por consequência, não sensibilizar sua audiência;

c) relação entre Relevância Primária (RPri) e Relevância Projetada (RPro): a RPri será responsável por introduzir o fato apurado no processo de produção jornalística; a RPro será responsável pelo destaque a dar à notícia, produzida a partir da RPri. Pode ser que essas relevâncias coincidam, mas pode ser que não. Há casos de notícias sabidamente de baixa RPri que recebem títulos apelativos (alta RPro) com a intenção comunicativa de gerar um efeito de relevância que não será sustentado pela intenção informativa. Tal discrepância denota tanto diferenças de entendimento entre os membros da equipe jornalística quanto tentativas de atrair, com artimanha eticamente questionável, a atenção da audiência;

d) relação entre Relevância Projetada (RPro)e Relevância Percebida (RP): este é um ponto extremamente crítico, quando a RPro pelos jornalistas é confrontada com a RP pela audiência. Os desencontros podem ocorrer porque: 1) a equipe jornalística não comunicou adequadamente sua RPro, sendo um problema essencialmente de construção da mensagem (da notícia e da edição); ou 2) a equipe jornalística não avaliou mesmo adequadamente a RPro do fato objeto da notícia, produzindo uma mensagem desprovida de relevância para a audiência. Nesse segundo caso, o problema pode ter sido gerado nos pontos a, b e c;

e) relação entre Relevância Percebida $(R P)$ e Expectativa de Relevância $(E R)$ : este ponto crítico afeta sobretudo os métodos de sondagem das Expectativas da Audiência. Pode acontecer de esses métodos colherem impressões que não se efetivem quando do consumo do produto. Por exemplo, quando dos processos de sondagem, os membros da audiência informarem certas expectativas (racionalmente motivadas) que não são efetivas na recepção das mensagens jornalísticas produzidas com base naquela sondagem; induzem uma expectativa que não corresponde à expectativa efetiva.

Todos esses pontos críticos tornam o processo de avaliação de relevância extremamente complexo - razão pela qual, sem a intenção de ter sido exaustivo na exploração do problema, este texto pretendeu equacionar uma forma de entendê-lo que possa orientar novas pesquisas com vistas a desenvolver ferramentas e processos destinados a dar suporte ao trabalho jornalístico. 
ALTHEIDE, D. Creating reality. Beverly Hills: Sage, 1976.

BARROS FILHO, C. de. Ética na comunicação. Da informação ao receptor. São Paulo: Moderna, 1995.

BERTRAND, C.-J. O arsenal da democracia: sistemas de responsabilização da mídia. Tradução de Maria Leonor Loureiro. Bauru, SP: Edusc, 2002.

COSTA, J. C. A teoria da relevância e as irrelevâncias da vida cotidiana. Linguagem em (Dis) curso, Tubarão, v. 5, n. esp., p. 161-169, 2005.

COSTA, J. C. Relevância, kluges, emoções: reflexões provocativas. In: CAMPOS, J.; RAUEN, F. J. (Org.). Tópicos em teoria da relevância. Porto Alegre: EDIPUCRS, 2008. p. 10-25.

CHAPARRO, M. C. Pragmática do Jornalismo: buscas práticas para uma teoria da ação jornalística. São Paulo: Summus, 1994.

CORNU, D. Jornalismo e verdade: para uma ética da informação. Tradução de Armando Pereira da Silva. Lisboa: Instituto Piaget, 1994.

ECO, U. Lector in fabula: cooperação interpretativa nos textos narrativos. São Paulo: Perspectiva, 1993.

ERBOLATO, M. L. Técnicas de codificação em Jornalismo: redação, captação e edição no jornal diário. Petrópolis: Vozes, 1978.

FEITOZA, L. do N. S. Relevância jornalística: análise e teste de ferramenta para fins de avaliação de qualidade e accountability. 2016. Dissertação (Mestrado em Comunicação) - Programa de Pós-Graduação em Comunicação, Universidade Federal de Sergipe (UFS), São Cristóvão, 2016.

FENGLER, S.; EBERWEIN, T; LEPPIK-BORK, T.; LÖNNENDONKER, J.; PIES, J. Introduction: Media accountability - Basic concepts and theoretical foundations. In. FENGLER, S., EBERWEIN, T., MAZZOLENI, G., PORLEZZA, C., RUSS-MOHL, S. (Org.). Journalists and Media Accountability: An International Study of News People in the Digital Age. New York: Peter Lang, 2014. p. 8-29.

FRANCISCATO, C. E. Considerações metodológicas sobre a pesquisa aplicada em jornalismo. In: CONGRESSO BRASILEIRO DE PESQUISADORES EM JORNALISMO (SBPJOR). 4., Brasília: Anais... Brasília: SBPJor, 2006.

FRANCISCATO, C. E. A fabricação do presente: como o jornalismo reformulou a experiência do tempo nas sociedades ocidentais. São Cristóvão: Editora UFS; Aracaju: Fundação Oviêdo Teixeira, 2005.

GALTUNG, J.; RUGE, M. H. A apresentação do noticiário estrangeiro. In: TRAQUINA, N. Jornalismo. Questões, teorias e 'estórias. Lisboa: Vega, 1999, p. 61-73.

GANS, H. Deciding what's news. New York: Pantheon Books, 1979.

GENRO FILHO, A. O segredo da pirâmide. Para uma teoria marxista do jornalismo. Porto Alegre: Ortiz, 1987.

GENTILLI, V. Democracia de massas: jornalismo e cidadania. Porto Alegre: Editora da PUC-RS, 2005.

GOMES, W. Jornalismo Fatos e Interesses: Ensaios de teoria do jornalismo. Florianópolis: Insular, 2009. $112 \mathrm{p}$.

GREISDORF, H. Relevance: An interdisciplinary and information science perspective. Informing Science, v. 3, n. 2, p. 67-72, 2000.

GUERRA, J. L. O percurso interpretativo na produção da notícia. São Cristóvão: Editora UFS; Aracaju: Fundação Oviêdo Teixeira, 2008.

GUERRA, J. L. Guia da Agenda Jornalística (GAJ) na perspectiva de uma proposta de Pesquisa Aplicada em Jornalismo (PAJ). Brazilian Journalism Research, v. 12, n. 3, 2016.

HALL, S.; CRITCHER, C.; JEFFERSON, T.; CLARKE, J.; BRIAN, R. A produção social das notícias. O mugging nos media. In: TRAQUINA, N. Jornalismo. Questões, teoria e "estórias". Lisboa: Vega, 1993: 224-248.

KOVACH, B.; ROSENSTIEL, T. The elements of journalism. What News People Should Know and the Public Should Expect. New York: Crown Publishers, 2001.

KUNCZIK, M. Conceitos de jornalismo: norte e sul; tradução Rafael Varela Jr. São Paulo: Editora da Universidade de São Paulo, 1997.

LAGE, N. Gramática do texto jornalístico. 1999. Aulas.

LIPPMANN, W. Opinião pública. 2. ed. Petrópolis, RJ: Vozes, 2010

MACHADO, E. Dos estudos sobre o jornalismo às teorias do jornalismo (Três Pressupostos para a

Consolidação do Jornalismo como Campo de Conhecimento). E-Compós - Revista da Associação 
Nacional dos Programas de Pós-Graduação em Comunicação. Ed.1, dez. 2004. Disponível em: http://www.compos.org.br/e-compos. Acesso em: 13 jun. 2016.

MACHADO, E.; SANT'ANA, J. Limitações metodológicas na pesquisa em jornalismo: um estudo dos trabalhos apresentados no GT de Jornalismo da COMPÓS (2000-2010). Pauta Geral, v. 1, p. 29-45, 2014.

MCQUAIL, D. Media performance. Mass Communication and the Public Interest. London, Thousand Oaks, New Delhi: Sage Publications, 1992.

MCQUAIL, D. Audience Analysis. London: Sage Publication, 1997.

MCQUAIL, D. Media Accountability and Freedom of Publication. Oxford; New York: Oxford University Press, 2003.

MEDITSCH. E. Estudos em Jornalismo. Revista Brasileira de Ciências da Comunicação. Vol XXVII, ${ }^{\circ}$ 2, jul/dez 2004. São Paulo: INTERCOM, 2004, p. 93-107. Disponível em:

http://www.portcom.intercom.org.br/revistas/index.php/revistaintercom/article/viewFile/1070/971. Data de acesso: 13/06/2016.

MEYER, P. Os jornais podem desaparecer? Como salvar o jornalismo na era da informação. São Paulo: Contexto, 2007.

MOLOTCH, H.; LESTER, M. As notícias como procedimento intencional. Acerca do uso estratégico de acontecimentos de rotina, acidentes e escândalos. In.: TRAQUINA, Nelson. Jornalismo. Questões, teorias e "estórias". Lisboa: Vega, 1993. p. 34-51.

OCDE. Manual de Frascati. Medição de atividades científicas e tecnológicas: Tipo de metodologia proposta para levantamentos sobre pesquisa e desenvolvimento experimental. OCDE/F-Iniciativas, 2005. Disponível em: http://www.mct.gov.br/upd_blob/0225/225728.pdf

RAUEN, F. Teoria da relevância e gêneros textuais: interfaces possíveis. SIMPÓSIO INTERNACIONAL DE ESTUDOS DE GÊNEROS TEXTUAIS (SIGET), Tubarão, Santa Catarina, 2007. Disponível em: http://linguagem.unisul.br/paginas/ensino/pos/linguagem/eventos/cd/Port/51.pdf. Acesso em: 20 jun. 2015.

RAUEN, F. J. Sobre relevância e irrelevâncias. In: CAMPOS, J.; RAUEN, F. J. (Org.). Tópicos em teoria da relevância. Porto Alegre: EDIPUCRS, 2008. p. 25-56.

ROSCHO, B. Newsmaking. Chicago and London: The University of Chicago Press, 1975.

SANTOS, L. N. Os valores-notícia na literatura jornalística: conceitos, elencos e operacionalização. 2014. 59 p. Trabalho de Conclusão de Curso (Graduação) - Departamento de Comunicação Social,

Universidade Federal de Sergipe, São Cristóvão, 2014.

SHOEMAKER, P. J. Gatekeeping. Thousand Oaks: Sage Publications, 1991.

SHOEMAKER, P. J.; COHEN, A. A. News around the world: content, practitioners, and the public. New York, Estados Unidos: Routledge, 2006.

SILVA, G. Para pensar critérios de noticiabilidade - estudos em jornalismo e mídia In: Programa de Pós-graduação em Jornalismo e Mídia da Universidade Federal de Santa Catarina. Florianópolis: UFSC, 2005.

SPERBER, D.; WILSON, D. Relevância: Comunicação e cognição. Tradução: Helen Santos Alves. Lisboa: Fundação Calouste Gulbenkian, 2001.

SPERBER, D.; WILSON, D. Teoria da relevância. Linguagem em (Dis) curso, Tubarão, v. 5, n. Especial, p. 221-268, 2005.

SPERBER, D.; WILSON, D. Posfácio da edição de 1995 de "relevância: comunicação \& cognição".

Linguagem em (Dis)curso, Tubarão, v. 5, n. Especial, p. 171-220, 2010.

TRAQUINA, N. Teorias do jornalismo. Florianópolis: Insular, 2004.

TUCHMAN, G. La producción de la noticia: estudio sobre la construcción de la realidad. Tradução de Héctor Borrat e revisão de Joaquim Ramanguera i Ramió. Barcelona: Ediciones Gilli, 1983.

WARREN, N. Carl. Géneros periodísticos informativos. Barcelona: ATE.,1975

WOLF, M. Teorias da Comunicação. 10. ed. Lisboa: Editorial Presença, 2009.

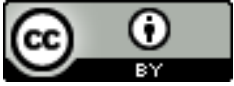

Este texto está licenciado com uma Licença Creative Commons Atribuição 4.0 Internacional 